\title{
La autonomía profesional. Competencia clave para el docente en Educación Comercial
}

\section{Professional Autonomy. Key Competence for Teachers in Commercial Education}

\author{
Isabel Araya Muñoz' \\ Facultad de Ciencias Sociales \\ Universidad Nacional \\ Heredia, Costa Rica \\ isaaraya@yahoo.com \\ Carolina España Chavarría ${ }^{2}$ \\ Facultad de Ciencias Sociales \\ Universidad Nacional \\ Heredia, Costa Rica \\ cespanac@yahoo.com.mx
}

Recibido 31 de enero de 2012 • Corregido 13 de junio de 2012 • Aceptado 28 de junio de 2012

Resumen. La forma en la cual se materializa la autonomía docente, concebida como parte del camino transitado por el colectivo docente en vías de apropiarse del conocimiento disciplinar y las competencias pedagógicas requeridas para el ejercicio de su función, es el eje de interés que provoca este escrito. Parte del éxito de la Educación Comercial se requiere de la urgida transformación de la función docente para el desarrollo de competencias claves provocadoras de la integración interdisciplinaria, el liderazgo académico y administrativo, y el uso de pedagogías contemporáneas. El grado de conciencia conseguido por el grupo docente sobre el impacto de los aprendizajes que promueve en el contexto educativo le permitirá empoderarse del conocimiento que resulte de la vinculación entre teoría y práctica, elemento clave para su autonomía profesional.

Palabras claves. Competencias, autonomía docente, conocimiento, autonomía profesional, Educación Comercial, gestión administrativa, secretariado.

\footnotetext{
Académica de la Facultad de Ciencias Sociales de la Universidad Nacional de Costa Rica. Máster en Docencia Universitaria y en Planificación Curricular. Docente e investigadora de la Escuela de Secretariado Profesional de la Universidad Nacional de Costa Rica.

2 Académica de la Facultad de Ciencias Sociales de la Universidad Nacional de Costa Rica. Egresada del Doctorado en Políticas y Prácticas de Innovación Educativa para la Sociedad del Conocimiento por la Universidad de Almería, España. Docente en el área de las Ciencias de la Educación y la Enseñanza del Inglés.
} 
URL: http://www.una.ac.cr/educare

\begin{abstract}
The way in which the teaching autonomy is materialized, considered as part of the path traveled by the teaching community on their way to become owners of the disciplinary knowledge and the required pedagogical competencies to practice their role has motivated this paper. For success, Commercial Education requires the urgent transformation of the teaching role and the development of key competences to promote interdisciplinary integration, academic and administrative leadership and the use of contemporary pedagogies. The level of awareness reached by the teaching group about the impact of the learning that is promoted within the educational context will allow the empowerment of the knowledge that comes from the relationship between theory and practice-key element for professional autonomy.
\end{abstract}

Keywords. Competencies, teaching autonomy, knowledge, professional autonomy, Commercial Education, administrative management, secretarial profession.

\title{
Introducción
}

En la actualidad, las instituciones educativas, incluida la universitaria, están llamadas a dotarse de un cuerpo docente capaz de desarrollar diversas competencias que le posibiliten el ejercicio de su función de manera autónoma.

La señal para alcanzar la autonomía profesional para el ejercicio de la función docente resulta a partir del procesamiento de la información hacia los conocimientos prácticos, claros y relevantes que, en su calidad de mediador/a activo/a del proceso, le exigen realizar como parte del desafío para el empoderamiento del saber.

Desde esta perspectiva se pretende analizar la autonomía profesional como competencia clave para quien imparte docencia en Educación Comercial, área profesional cuyo objeto de estudio es definido, por Araya (2011), como la promoción de espacios pedagógicos para el desarrollo de competencias dirigidas a la gestión de apoyo administrativo, en las diferentes empresas e instituciones dedicadas a una diversidad productiva: servicios, comercio, agrícola, profesional, industrial, educación, etc.

Se considera que el objeto de estudio de la Educación Comercial integra saberes científicos y disciplinarios: educativos, desarrollo humano, comunicación en inglés y en español, ciencias secretariales, psicología, educación, investigación, cultura general, derecho, archivística, tecnológicas de la información y la comunicación, y gestión empresarial (Araya, 2011). A partir de esto, los planes curriculares de los diversos programas de estudio establecidos en este campo particular, resaltan la función del docente y la propuesta pedagógica enriquece la formación de personas técnicas o profesionales de la gestión de oficinas con capacidades y cualidades que respondan a sus necesidades productivas y de desarrollo humano.

Por ello, la reflexión y acción por parte del profesorado en el proceso educativo permite indagar en lo que define el papel de la autonomía, desde lo que establece el currículo, en conjunto con lo que dicta la pedagogía en términos de productividad del conocimiento. La autonomía 
profesional, entendida como el proceso requerido para empoderarse del conocimiento, consta, según Flórez (1994), de tres momentos relevantes en la valoración del conocimiento: la cotidianidad, la reflexión y la afirmación. Su objetivo es contribuir con el quehacer didáctico, al permitirle al profesional generar y promover prácticas pedagógicas competentes.

La dinámica productiva del conocimiento en función de la autonomía profesional como parte del proceso educativo con significancia para ambos, docentes y discentes, es el prácticum pedagógico, en el cual se evidencia lo relevante y funcional del conocimiento para el empoderamiento del saber y su puesta en escena. Asimismo, en materia de gestión de apoyo administrativo, la aplicación teórica y práctica se consideran ricas en posibilidades de estudio de casos dentro de las áreas o apartados competenciales: producción documental, soporte organizacional, recursos tecnológicos y administración de la información.

Lo anterior invita a recordar uno de los atributos más preciados en el mundo de los negocios, conocido con el nombre de know how (el saber cómo se hace), que le brinda la veteranía o madurez de experiencia a quien se desempeña en esa área. En el campo pedagógico, se considera igualmente importante valorar la experticia alcanzada a lo largo de la práctica, no tanto por los años desempeñados en su ejercicio, sino, más bien, por la profundidad de análisis, criticidad, inventiva y demás, con la que fuese asumida dicha función.

La responsabilidad y el reto que supone la promoción de aprendizajes significativos, funcionales y pertinentes conducen al empoderamiento del conocimiento y al desarrollo de competencias y habilidades requeridas para el ejercicio autónomo de la profesión.

Los procesos de formación docente serán, entonces, de orden permanente y versarán sobre el desarrollo de competencias ético-profesionales que permitan transformar la actitud por una más reflexiva, analítica, auto-dirigida, dispuesta a asumir riesgos y a aprender de los desafíos que le impone el contexto.

Las anteriores capacidades son consideradas por Marchesi (2007, p. 37) como necesarias para que se logre "(...) adquirir, actualizar y consolidar a lo largo de la vida profesional tanto las competencias profesionales como sus disposiciones básicas referidas al equilibrio afectivo y a la responsabilidad moral".

Continuando con la relación que subyace entre formación docente y desarrollo de competencias para la autonomía profesional, se hace necesario valorar los niveles de profundidad y permanencia con la que se lea lo acontecido dentro y fuera del contexto aprendiente, condición que permitirá aproximar las realidades del entorno a los significantes que determinan la práctica. Por lo tanto, y coincidiendo con lo establecido en el 2007 por Marchesi, la mera adquisición de conocimientos, capacidades y demás atributos adquiridos en los procesos de formación y capacitación docente no garantizan ni acreditarán una determinada competencia del profesorado. Más bien se hace necesario 
que dichas competencias se trasladen a la práctica docente y se demuestren ahí, donde deberán ser puestas en escena para su respectiva evaluación.

Tal y como lo evidencia Marchesi, el hacer didáctico va más allá de un saber técnicodisciplinar; por el contrario, obliga al desarrollo de múltiples competencias, entre ellas la capacidad de síntesis, la cual permite el aprovechamiento productivo de los aprendizajes emergentes a lo largo de la práctica docente (disciplinar, de relaciones con educandos y colegas, de la vida diaria, entre otros), condición que, al ser llevada al seno de la práctica, se constituye en modelo y orientación didáctica; y le permite, al estudiantado, aprender y entender interrelacionando saberes y experiencias para una construcción autónoma del conocimiento. De allí la consideración de Gardner (2005) al afirmar que el avance en el proceso de formación del estudiantado está en gran medida condicionado por la capacidad del docente para sintetizar, relacionar e identificar la información y los aprendizajes que pretende promover desde su práctica. Es decir, la responsabilidad del manejo de las llaves que abren el paraje simbólico de lo relevante recaerá en la conducción autónoma de la práctica docente, por cuanto, según Savater (1997, p. 16), “(...) La verdadera educación no sólo consiste en enseñar a pensar sino también en aprender a pensar sobre lo que se piensa (...)".

Cualesquiera de las competencias anteriormente valoradas como necesarias para el desarrollo autónomo de la profesión ameritan de un acompañamiento sustancial de humildad docente, condición de gran preciado valor y reconocimiento por parte de colegas y estudiantes. Bien lo decía Freire (2002): quien no es humilde no comprenderá que nadie tiene conocimiento ni maestría absoluta. Es decir, cuando los artífices del proceso (docente y discente) no reconocen su ignorancia o desconocimiento ante lo sucedido, los esfuerzos pedagógicos podrían no encontrar su lugar y el esfuerzo por aprender perdería su sentido.

Igualmente, la tolerancia representa un valor que, aunado a una actitud propositiva de respeto, de apertura para desaprender y construir nuevas formas de ver el mundo, permite el desarrollo autónomo profesional. No obstante, con esto y coincidiendo con Freire (2002), no se está diciendo que para lograr autonomía en la profesión docente sea necesario tolerar lo intolerable o enmascarar lo inadmisible: se refiere, más bien, a convivir con lo diferente y así cultivar nuestro conocimiento para potenciar nuestro ser y lograr un hacer enriquecido y significativo para la vida. Si no se logra promover una educación tolerante con lo que es diferente y ajeno a nuestra realidad de vida, no podremos conseguir que el estudiantado comprenda, valore y destaque las infinitas cualidades de millones de seres que habitan el mundo y "(...) lo máximo que podemos esperar es una paz precaria" (Gardner, 2005, p. 20).

También, la capacidad de decisión del docente representa una competencia necesaria en su labor formadora, ya que la toma de decisiones que dicho profesional realice infundirá seguridad personal y profesional, como también determinará su postura ante el saber, lo cual proyectará al estudiantado, quien asumirá la responsabilidad de adoptarlo como enseñanza de 
la difícil virtud de la decisión. Esto, por cuanto hay que recordar que, para muchos, la decisión tomada en la vida de un ser humano determina su camino, más allá de lo biológicamente heredado.

Por eso, el docente que carezca de claridad de decisión podría ser mal interpretado por su colectivo estudiantil y dicha incompetencia podría ser etiquetada, según Freire (2002), como una debilidad moral o incompetencia profesional, la cual alejaría la promoción de aprendizajes de la calidad buscada.

En las ideas anteriores se han diferenciado algunos rasgos que fundamentan la autonomía profesional. En educación y específicamente en la Educación Comercial de hoy, la cual va más allá de enseñar contenidos o enseñar tareas que serán medidas con estándares de calidad, se requiere de personal docente con la autonomía profesional como competencia clave.

A partir de las reflexiones hechas, ese talante profesional se caracteriza por:

- Poseer capacidad de estudiar la cotidianeidad, reflexionar sobre el actuar y reafirmar sus prácticas.

- Saber cómo se hace y para qué se hace.

- Tener experticia, más allá de dominio de contenidos, estudiar la realidad para la búsqueda de solución de los problemas (análisis de la realidad, criticidad, inventiva).

- Promover aprendizajes significativos, funcionales y pertinentes a la realidad productiva y a la calidad de vida de sí mismo y de la comunidad.

- Mostrar reflexión ética-profesional con principios de solidaridad y del bien común.

- Leer las líneas del contexto aprendiente y significante con maestría .

- Aprender y reaprender de las prácticas compartidas y solidarias.

- Reaccionar asertivamente para tomar decisiones en función de la buena práctica pedagógica.

- Cuidar de llevar al estudiantado a pensar, analizar y reflexionar sobre lo que aprende, cómo lo aprende y para qué lo aprende

Por tanto, la autonomía profesional no es solo un rasgo común del perfil del docente, es una competencia clave, producto de la madurez del desarrollo formativo y autoformativo. Esta, de acuerdo con Araya (2011), se fundamenta en tres ejes curriculares: integración interdisciplinaria, liderazgo académico y administrativo, y uso de pedagogías contemporáneas. 
URL: http://www.una.ac.cr/educare

La integración del currículo, desde el punto de vista disciplinar y de acuerdo con la propuesta de Torres (1998), es la oportunidad de análisis del proyecto educativo en la gestión del conocimiento, por medio de acciones conjuntas hacia una misma meta formativa. Exige trabajo en equipo, puesto que cada disciplina aporta al estudio del tema; al respecto, el docente asume su cuota en la construcción del conocimiento desde su área específica y lo contrasta o enriquece con las diversas disciplinas que lo afectan.

El liderazgo académico y el liderazgo administrativo responden a las cuestiones filosóficas, epistemológicas y psicopedagógicas que basan un proyecto formativo, por tanto, remiten a criterios de asunción de los deberes y obligaciones del docente y de los administradores curriculares para proveer una estructura que posibilite el logro de las metas educativas, a través del trabajo interdisciplinario, excelencia en el desempeño, profesionalización, capacitación permanente, disposición y adaptación a los cambios vertiginosos en la ciencia y las tecnologías de la comunicación y de la información, a los nuevos sistemas productivos y a las transformaciones culturales que se generan de los procesos de movilidad social y territorial. En ese sentido, el docente se enfrenta a una realidad a la cual debe responder con excelencia.

La aplicación de pedagogías contemporáneas motiva la operacionalización de situaciones de aprendizaje autónomas, la responsabilidad del estudiante en su propio desarrollo, el consenso entre los involucrados, la investigación acción-reflexión para estudiar e intervenir la realidad para transformarla, el fortalecer la interacción escuelacomunidad en el estudio de las necesidades individuales, formativas y de intervención social; todo esto basado en el liderazgo docente.

La autonomía profesional involucra saberes, actitudes y disposición para el logro de esa emancipación profesional. Así lo anotan 16 profesores de la especialidad de Educación Comercial, de diversas áreas geográficas y de diferentes niveles educativos de Costa Rica, (Araya, 2011), en una lista de capacidades y cualidades que se enmarcan en cuatro grandes áreas: cualidades humanas, conocimientos teóricos y prácticos, experiencia y formación continua y cualidades pedagógicas. Estas se resumen a continuación:

\section{- Cualidades humanas}

Valores éticos, independencia personal, facilidad para trabajar con otras personas, y respeto a las condiciones comunitarias en cuanto a su desarrollo social y a la protección ambiental.

\section{- Conocimientos teóricos y prácticos}

Dominio de la especialidad en las cuatro áreas básicas del Secretariado: producción documental, soporte organizacional, recursos tecnológicos y administración de información. Involucra el saber y el saber hacer. 


\section{- Experiencia y formación continua}

Independencia para autocapacitarse y proyectarse en la experiencia real. Dominio de las futuras actividades profesionales del estudiantado. Comprensión del saber y del saber hacer para enseñar con propiedad.

\section{- Cualidades pedagógicas} enseñar.

Gestión didáctica y pedagógica: planificación y entrega docente, saber aprender, saber

Esos elementos que diferencian a un docente autónomo son primicias de un desempeño con eficacia en los diversos papeles que le corresponde cumplir al profesional en Educación Comercial. Estos se asocian a su labor pedagógica prioritaria: la gestión administrativa docente, y la promoción de saberes para el desempeño de la profesión y la vida en general.

De acuerdo con Araya (2011), y sin pensar que el desarrollo de competencias se ajusta al cumplimiento de un listado de asuntos por hacer como garantía para alcanzar el éxito docente en Educación Comercial, se propone el desarrollo de ciertas capacidades para el logro de la autonomía profesional:

- Tener actitud de indagación para actualizarse para el logro de una entrega docente con coherencia, actualizada y motivadora.

- Aprender en forma continua, de manera que le permita la aplicación de recursos tecnológicos, técnicas y procedimientos acordes con las necesidades de los sectores productivos, comunitarios y ambientales.

- Poseer principios de convivencia social que le permitan actuar con valores éticos, el diálogo y la comunicación, que orienten su trabajo hacia la mejora de la sociedad por medio del trabajo interdisciplinario.

- Tener disposición para integrar la teoría con la práctica a partir de actividades de aprendizaje que orienten al estudio de la realidad para transformarla.

- Poseer capacidades profesionales para una entrega docente con calidad, esto involucra el dominio disciplinar y la docencia, en cuanto a saberes teóricos y prácticos para la administración de oficinas o secretariado, la didáctica, la pedagogía y la gestión administrativa docente. 
URL: http://www.una.ac.cr/educare

A manera de reflexión final, la autonomía del profesional en Educación Comercial, al igual que en las diversas profesiones académicas o de cualquier otra área, redunda en el desempeño laboral, en el auto-crecimiento personal y en el aporte al desarrollo social.

La Educación Comercial, en sus diversos programas de la especialidad, adquiere gran importancia en la economía de un país, por tanto, la docencia en esta área del saber tiene una gran responsabilidad al generar procesos de formación para el desarrollo de personas con firmeza para la toma de decisiones, propositivas y proactivas, con ética y valores, que no se constituyan en meros transmisores de contenidos sin mayor relación con los problemas sociales existentes.

La sociedad actual plantea el reto a la educación en cuanto a la formación de personas con competencias, pues las no competentes no tienen cabida en la sociedad actual. La impronta será la promoción de conocimientos intelectuales, de habilidades y actitudes de las cuales sea posible empoderarse de conocimiento y, consecuentemente, desarrollar autonomía. La búsqueda de significados y la generación de procesos educativos promotores del autoaprendizaje garantizará conocimientos permanentes.

Por tanto, el ejercicio de la docencia urge de un proceso resolutivo en el cual se aprende, se desaprende y se reaprende con pericia. Relacionar los diversos elementos contextuales, con actitud y con compromiso para potenciar al estudiante hacia niveles óptimos de progreso, será parte sustancial de los retos por asumir. La construcción de una renovada figura docente conducida por aprendizajes permanentes, reflexivos, analíticos y sintéticos permitirá una construcción autónoma del conocimiento y, por consiguiente, de la profesión, responsable a su vez de revelar lo esencial del objeto de estudio, en este caso en particular, el que se refiere a la Educación Comercial.

\section{Referencias}

Araya, I. (2011). Diagnóstico curricular y propuesta de perfil profesional por competencias de la Licenciatura en Educación Comercial. (Tesis de maestría inédita). Universidad de Costa Rica.

Flórez, R. (1994). Hacia una pedagogía del conocimiento. Bogotá: McGraw-Hill.

Freire, P. (2002). Pedagogía de la autonomía. Argentina: Siglo XXI.

Gardner, H. (2005). Las cinco mentes del futuro. España: Paidós Ibérica

Marchesi, A. (2007). Sobre el bienestar de los docentes: Competencias, emociones y valores. Madrid: Alianza.

Savater, F. (1997). El valor de educar. Barcelona: Ariel.

Torres, J. (1998). Globalización e interdisciplinariedad: El currículum integrado (3a ed.). Madrid: Ediciones Morata. 